\title{
Prokaryotic expression and identification of scavenger receptor B2
}

\author{
T. XU, Z. LIN, CH. WANG, Y. LI, M. ZHAO, L. HUA, B. ZHU* \\ Central Laboratory, Guangzhou Women and Children's Medical Center, Guangzhou Medical University, Guangzhou 510120, \\ Guangdong, P. R. China
}

Received November 16, 2016; revised May 19, 2017; accepted January 9, 2018

\begin{abstract}
Summary. - There is still no effective clinical antiviral drug against human enterovirus 71 (EV71) infection, which causes hand, foot and mouth disease (HFMD) in children. Scavenger receptor class B member 2 (SCARB2) is an important receptor of EV71 as it plays a vital role in the early steps of viral infection. In this study, recombinant SCARB2 protein was expressed and purified in a prokaryotic expression system, and was identified by western blot with a monoclonal antibody and mass spectrometry analysis. Detection of the sera from mice immunized with the recombinant SCARB2 protein using ELISA and western blot showed good immunogenicity of the recombinant protein. Furthermore, in the neutralization test cytopathic effect was significantly decreased when EV71 was incubated with the immune sera before infection. In summary, the SCARB2 protein was expressed successfully, and the immune sera showed obvious antiviral effect against EV71. This study provides useful information about the interaction mechanism between SCARB2 and EV71, and is also helpful for further clinical treatment research of HFMD.
\end{abstract}

Keywords: scavenger receptor class B member 2; enterovirus 71; prokaryotic expression; immunogenicity; neutralization test

\section{Introduction}

Hand, foot, and mouth disease is a common febrile disease occurring mainly in infants and children under 5 years (Chatproedprai et al., 2015; Huang et al., 2009; Li et al., 2015). HFMD is usually mild and self-limited. However, various neurological symptoms may occur in some infants, such as brainstem encephalitis, aseptic meningitis, acute flaccid paralysis and fatal neurogenic pulmonary oedema (Chatproedprai et al., 2010; Chen et al., 2012; Ortner et al., 2009; Tu et al., 2007). In recent years, epidemic or sporadic outbreaks of neurovirulent EV71 infections have been reported mainly in Southeast Asia, including Taiwan, Malaysia, Singapore, Japan, and China(Lin et al., 2012; Sarma, 2013; Xing et al., 2014; Zhang et al., 2012). Enterovirus 71 (EV71) belongs to the Enterovirus genus within the Picornaviridae

*Corresponding author. E-mail: zhubing0327@hotmail.com; phone: +86-020-81330740.

Abbreviations: EV71 = enterovirus 71; HFMD = hand, foot and mouth disease; SCARB2 = scavenger receptor class B member 2 family. It is one of the main pathogens of HFMD which cause fatal neurological diseases (Lee and Chi, 2014; ManLi et al., 2012).

Determining the specific cell receptor is essential to clarify the pathogenic mechanism in the early steps of EV71 infection (Wang et al., 1999; Yamayoshi and Koike, 2011). Currently, numbers of cellular receptors and host factors participating in EV71 infection have been identified, such as SCARB2 (Yamayoshi and Koike, 2011), PSGL-1(Yang et al., 2009), vimentin (Du et al., 2014) and others. A variety of evidences suggest that SCARB2 plays a critical role in EV71 infection (Yamayoshi et al., 2009). SCARB2, a specific glucose cerebrosides esterase binding ligand, is a high-density lipoprotein. It is a type II transmembrane glycoprotein sialic acid, with the relative molecular mass of $85 \mathrm{kDa}$. SCARB2 is one of the most abundant proteins in the lysosomal membrane and takes part in membrane transport. It is pivotal in the recognition of the lysosomal compartment (Kuronita et al., 2002) and works as a receptor for the mannose-6-phosphate-independent transportation from glucocerebrosidase to lysosome (Blanz et al., 2010). To this 
day, there is still no effective clinical antiviral drug against EV71 infection. Research and development of safe and effective vaccine, early diagnostic kits and effective antiviral drugs is pressing. In this study, we expressed recombinant SCARB2 protein and proved its immunogenicity. This study has an important benefit for improvement of prevention and therapy of HFMD.

\section{Materials and Methods}

Cells, virus, animals. RD cells (human rhabdomyosarcoma cell line) were obtained from Shanghai Cell Bank of Chinese Academy of Sciences. Enterovirus 71 (EV71) C4 genotype (GenBank Acc. No. FJ360545.1) used in this study was isolated and preserved in Guangzhou Women and Children's Medical Center. Six weeks old female BABL/c mice were obtained from Animal Experiment Center of Guangdong Province and performed according to the protocols and guidelines of the Ethics Committee of Animal Experiment Center of Guangdong Province (permit number: SCXK 2013-0002).

Amplification of SCARB2 gene. RD cells were cultured in Dulbecco's Modified Eagle's Minimal Essential Medium (DMEM, Life, USA) containing $100 \mathrm{U} / \mathrm{ml}$ penicillin, $50 \mathrm{U} / \mathrm{ml}$ streptomycin and $10 \% \mathrm{FBS}$ (Life) at $37^{\circ} \mathrm{C}$ with $5 \% \mathrm{CO}_{2}$ atmosphere. After RNA isolation (RNA extraction kit; Takara, Japan) from cells, the gene of SCARB2 was amplified by reverse transcription PCR (One step RT-PCR kit, Takara). cDNA was synthesized at the following conditions: $30^{\circ} \mathrm{C}$ for $10 \mathrm{~min}, 42^{\circ} \mathrm{C}$ for $30 \mathrm{~min}$ and $99^{\circ} \mathrm{C}$ for $5 \mathrm{~min}$ with random 9-mer primers. PCR reaction was then performed at the following conditions: $94^{\circ} \mathrm{C}$ for $5 \mathrm{~min}$ followed by 33 cycles at $94^{\circ} \mathrm{C}$ for $45 \mathrm{~s}, 56^{\circ} \mathrm{C}$ for $90 \mathrm{~s}, 72^{\circ} \mathrm{C}$ for $2 \mathrm{~min}$. The sequences of primers were: forward 5' GCGGAATTCATGGGCCGATGCTGCTTC TACA 3 ' and reverse 5' CATCTCGAGTTAGGTTCGAATGAG GGGT 3' (Sangon Biotech,China). The products were analyzed by $1.0 \%$ agarose gel electrophoresis and were extracted using a DNA gel extraction kit (Takara).

Construction of the expression vector pET28a-SCARB2. The extracted PCR products were digested with XhoI and EcoRI and inserted into the pET28a plasmid (Takara) which was previously digested with the same enzymes, resulting in the recombinant plasmid pET28a-SCARB2. Then the recombinant pET28a-SCARB2 or pET28a purified plasmids (Plasmid purification kit; Takara) were transformed into Escherichia coli DH5a cells (Takara). Transformed clones were inoculated into $5 \mathrm{ml}$ of Luria-Bertani (LB) medium including $100 \mu \mathrm{g} / \mu \mathrm{l}$ kanamycin at $37^{\circ} \mathrm{C}$ overnight, followed by extraction and digestion with XhoI and EcoRI (Takara). The recombinant plasmid was confirmed by restriction enzyme digestion and sequencing (Invitrogen, China). Finally, the verified pET28aSCARB2 plasmid was transformed into Escherichia coli BL21 (DE3) (Takara) cells for protein expression.

Expression and purification of recombinant protein SCARB2. Expression and purification of recombinant protein was done according previously described methods (Manat et al., 2016). The positive clones were cultivated in $5 \mathrm{ml} \mathrm{LB}$-kanamycin medium at $200 \mathrm{rpm}$ and $37^{\circ} \mathrm{C}$ overnight. Next day, the overnight cultures of cells carrying the pET28a-SCARB2 vectors were diluted at 1:100 in $500 \mathrm{ml}$ fresh LB-kanamycin medium and left to grow in incubator at $200 \mathrm{rpm}$ and $37^{\circ} \mathrm{C}$ for $5 \mathrm{~h}$. When the optical density of the culture at $600 \mathrm{~nm}\left(\mathrm{OD}_{600}\right)$ reached 0.5 , isopropyl-beta-thio-galactopyranoside (IPTG; Beyotime Biotechnology, China) was added to a final concentration of $1 \mathrm{mmol} / \mathrm{l}$. After additional incubation for $4 \mathrm{~h}$ at $37^{\circ} \mathrm{C}$, the bacterial pellets were harvested by centrifugation at 3,000 $\times \mathrm{g}$ for $30 \mathrm{~min}$ and the concentration was measured with a BCA protein detection kit (Beyotime Biotechnology, China). The expressed proteins were confirmed by SDS-PAGE. Then the SCARB2 was after staining with $0.25 \mathrm{~mol} / \mathrm{K} \mathrm{KCl}$ solution and cutting extracted from the gel. The gel was washed by distilled water and crushed. The crushed gel was after 3 cycles of freez-thawing collected by centrifugation at $12,000 \times \mathrm{g}$ for $2 \mathrm{~min}$. The gel extract in $500 \mu \mathrm{l}$ phosphate-buffered saline (PBS) was used for animal immunization. The concentration of the purified recombinant SCARB2 protein was determined and used for ELISA.

Identification of recombinant protein SCARB2. The SDS-PAGE gel containing the SCARB2 protein was stained with Coomassie blue (Beyotime Biotechnology). Target bands were cut and analyzed by mass spectrometry, followed by sequence analysis in NCBI database. Proteins were transferred onto PVDF membrane (Millipore, USA), and blocked with 5\% non-fat milk in TBST buffer. The membrane was then incubated with mouse His antibody $(1: 1000)$ for $1 \mathrm{~h}$ at $37^{\circ} \mathrm{C}$ and HRP labeled goat anti-mouse IgG (1:3,000; Sigma, USA) for $30 \mathrm{~min}$ at $37^{\circ} \mathrm{C}$. Finally, the bands were detected by DAB substrate (Beyotime Biotechnology).

Indirect ELISA of recombinant SCARB2 interaction with EV71. To analyze the interaction of recombinant SCARB2 protein with EV71 or EV71-VP1, the enzyme-linked immunosorbent assay (ELISA) was conducted as previously reported (Ding et al., 2015). Briefly, the 96-well microtiter plates were coated with $2.5 \mu \mathrm{g} / \mathrm{ml}$ recombinant SCARB2 protein in $50 \mathrm{mmol} / \mathrm{l}$ carbonate buffer ( $\mathrm{pH}$ 9.6) at $4^{\circ} \mathrm{C}$ overnight and then blocked with $5 \%$ non-fat milk in PBST for $2 \mathrm{~h}$ at $37^{\circ} \mathrm{C}$. After being washed three times with PBST, $100 \mu \mathrm{l}$ of EV71 (10-fold dilution in PBST) or $5 \mu \mathrm{g} / \mathrm{ml}$ of EV71-VP1 protein (100-fold dilution in PBST) were added and incubated at $37^{\circ} \mathrm{C}$ for $1 \mathrm{~h}$. Solutions were removed and $100 \mu \mathrm{l} /$ well of VP1 monoclonal antibody (Abcam, UK) was added and incubated for $2 \mathrm{~h}$ at $37^{\circ} \mathrm{C}$. After that, $100 \mu \mathrm{l} /$ well of HRP labeled goat anti-mouse IgG was added and incubated for $40 \mathrm{~min}$ at $37^{\circ} \mathrm{C}$. The plates were developed using tetramethylbenzidine and hydrogen peroxide mixture. The reaction was stopped with $50 \mu \mathrm{l}$ of $2 \mathrm{~mol} / \mathrm{l}$ of $\mathrm{H}_{2} \mathrm{SO}_{4}$, and the absorbance at $450 \mathrm{~nm}$ was measured on microplate reader (Bio-Rad, USA). The cutoff value was calculated as 0.1 plus mean $\mathrm{OD}$ value of the negative control. The values higher than 1.0 were indicated as a positive result.

Immunogenicity experiment. Immunogenicity of recombinant SCARB2 protein was detected as described previously (Ch'ng et al., 2011). Six weeks old female BALB/c mice were randomly divided 
into two groups of three mice. Immunization of mice was carried out at day $0,14,28$ and 41. Purified recombinant SCARB2 protein with concentration of $200 \mu \mathrm{g} / \mathrm{ml}$ was emulsified with equal volume of Freund's complete adjuvant (Sigma, USA). A total of $500 \mu \mathrm{l}$ mixture was administered to the mice via intramuscular route. Sera from mice immunized with PBS were collected as negative control. Forty-two days after the primary immunization, mice were sacrificed and blood was collected for ELISA assay and western blot.

Immunoreactivity of SCARB2 recombinant protein. The sera antibody titers were detected by ELISA. Briefly, the mice serum at the dilutions of $1: 80,1: 160,1: 320,1: 640,1: 1,280,1: 2,560,1: 5,120$ and 1:10,240 in PBS were incubated with recombinant SCARB2 protein coated in 96 -well microtiter plates for $1 \mathrm{~h}$ at $37^{\circ} \mathrm{C}$. After incubation with HRP labeled goat anti-mouse IgG, the values of $\mathrm{A}_{450}$ were recorded. The immunoreactivity of the recombinant SCARB2 was detected by western blot. The recombinant SCARB2 protein transferred onto PVDF membrane was incubated with SCARB2 polyclonal antibody for $1 \mathrm{~h}$ at $37^{\circ} \mathrm{C}$ and HRP labeled goat antimouse IgG for $30 \mathrm{~min}$ at $37^{\circ} \mathrm{C}$ and developed by DAB substrate.

Neutralization assay in vitro. The $50 \%$ tissue culture infectious dose $\left(\right.$ TCID $\left._{50}\right)$ of EV71 virus was detected as previously reported (Pourianfar et al., 2012). EV71 virus was diluted and gradient from $10^{-1}$ to $10^{-10}$ was added to RD cells in a 96-well plate. The cytopathic effect (CPE) was observed using an inverted microscope 5 days post infection. TCID $_{50}$ calculations were conducted using the ReedMuench formula. The method of neutralization test in vitro was performed as previously mentioned (Li et al., 2014). RD cells were prepared by seeding $2 \times 10^{5}$ cells per well in 96 -well plates. Fourfold serial dilutions $(1: 16,1: 64,1: 256,1: 1024)$ of immune sera were prepared in DMEM. Each dilution was done in quadruples and was challenged with or without equal volume of $200 \mathrm{TCID}_{50}$ of EV71 virus. After incubation for $1 \mathrm{~h}$ at $37^{\circ} \mathrm{C}$, the mixtures containing serially diluted sera and EV71 were further incubated at $37^{\circ} \mathrm{C}$ for 5 days. The neutralizing antibody titers were defined as the highest dilution of sera that prevented the occurrence of CPE.

\section{Results}

\section{Amplification of SCARB2 gene}

The SCARB2 gene was amplified from RD cells using RT-PCR and subjected to analysis with $1.0 \%$ agarose gel electrophoresis (Fig 1). The length of the amplified product with about 1300 bp correlated with SCARB2 gene. Gene comparison by BLAST (Kaur et al., 2016) showed that the amplified product was in 99\% homologous with SCARB2 gene from GenBank (BT0069391) (Fig. 2).

\section{Verification of recombinant plasmid by enzymatic digestion}

To confirm the recombinant plasmid pET28a-SCARB2, plasmid isolated from transformed E. coli BL21 (Takara) was digested by XhoI and EcoRI. Two distinct bands obtained at about 1359 bp and 5300 bp correlated with lengths of SCARB2 gene and pET28a plasmid, respectively (Fig. 1b).

\section{Expression of recombinant SCARB2 protein}

The pET28a-SCARB2 plasmid was transformed into $E$. coli BL21 cells. Positive clones were induced by IPTG to produce recombinant protein. To verify the recombinant SCARB2 protein, the E. coli cells were lysed, subjected to $10 \%$ SDS-PAGE and stained with Coomassie blue. Molecular weight of recombinant protein was $55 \mathrm{kDa}$ (Fig. 3a).

\section{Identification of recombinant protein SCARB2}

The recombinant SCARB2 protein was identified by western blot with His monoclonal antibody. The results indicate that the molecular weight of recombinant SCARB2 protein (a)

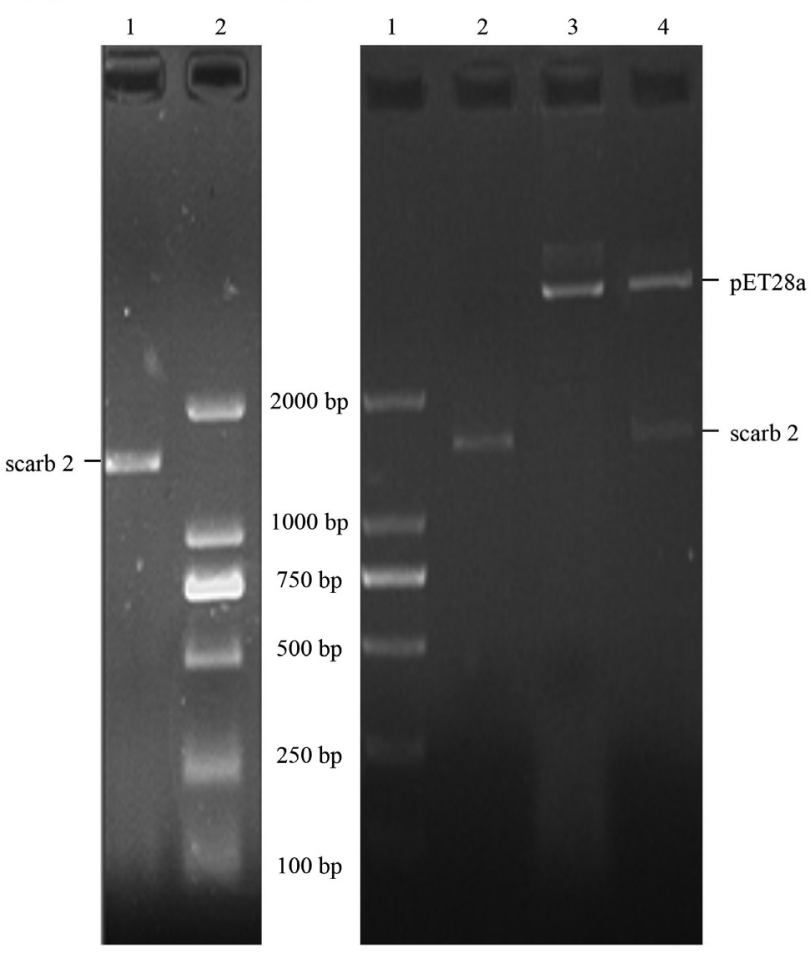

Fig. 1
Amplification of SCARB2 gene and construction of the recombinant plasmid

(a) Agarose gel electrophoresis of SCARB2 gene. Lane 1, amplified SCARB2 gene; lane 2, DL2000 DNA molecular marker. (b) Identification of recombinant plasmid by enzymatic digestion. Lane 1, DL2000 DNA molecular marker; lane 2, amplified SCARB2 gene; lane 3, pET28a plasmid; lane 4, recombinant pET28a-SCARB2 plasmid digested by EcoRI and XhoI. 


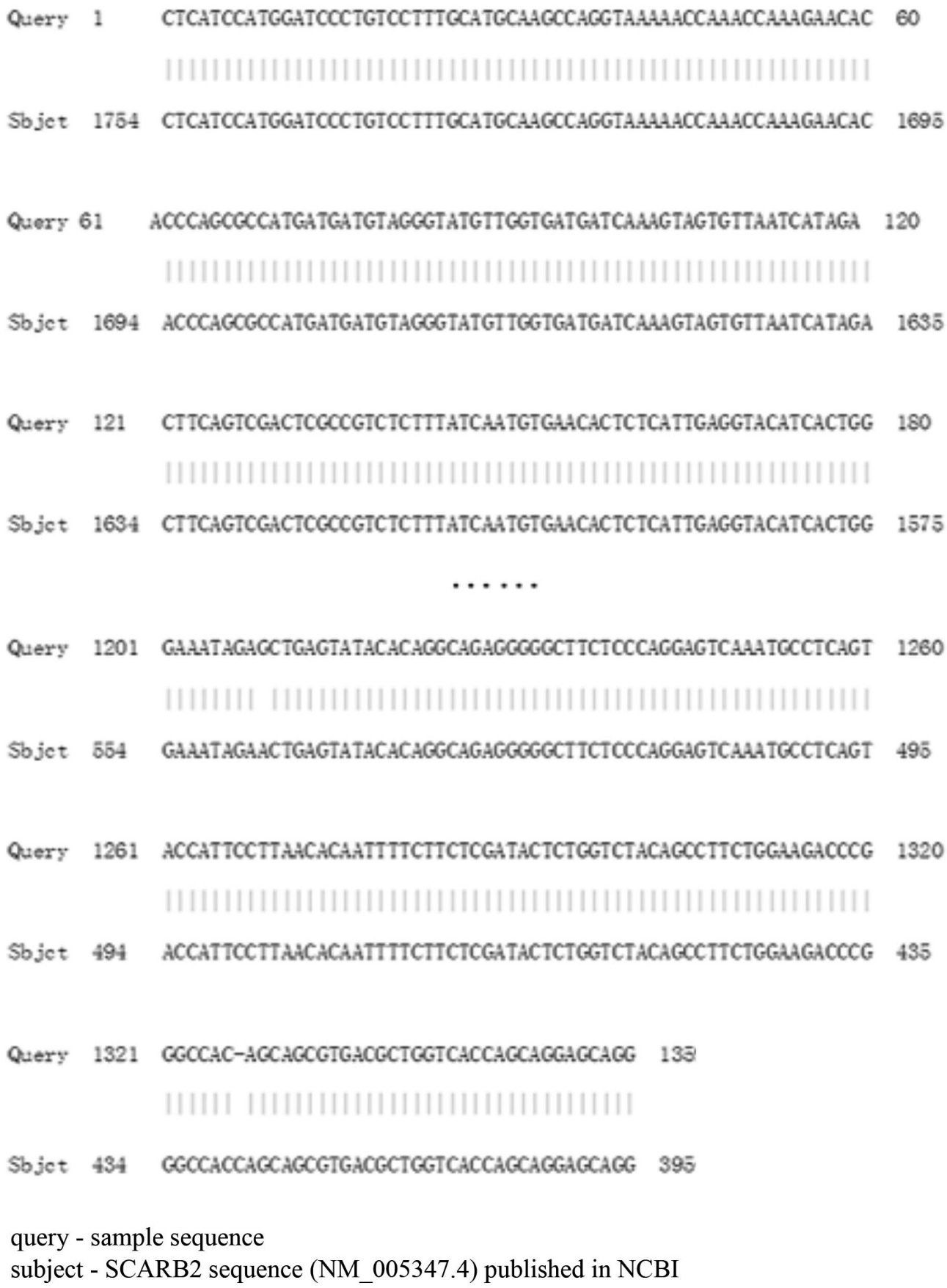

Fig. 2

Sequence analysis of SCARB2

The results of BLAST analysis show the highest homology in GenBank database SCARB2. Homo sapiens scavenger receptor class B member 2 (SCARB2), transcript variant 1, mRNA Sequence ID: ref NM 005506.3; length: 4780 bp; number of matches: 1; score: 2499; bits 1353; identities: 1358/1360 (99\%); gaps: $1 / 1360(0 \%)$; strand: plus/minus.

with tag was $55 \mathrm{kDa}$ (Fig. 3b). It also showed that His monoclonal antibody reacted with the lysate of induced E. coli, but did not react with the uninduced expression bacteria.
The obtained SCARB2 bands were cut from the Coomassie stained gel and analyzed by mass spectrometry. Protein sequence was acquired from NCBI, and protein score was 
(a)

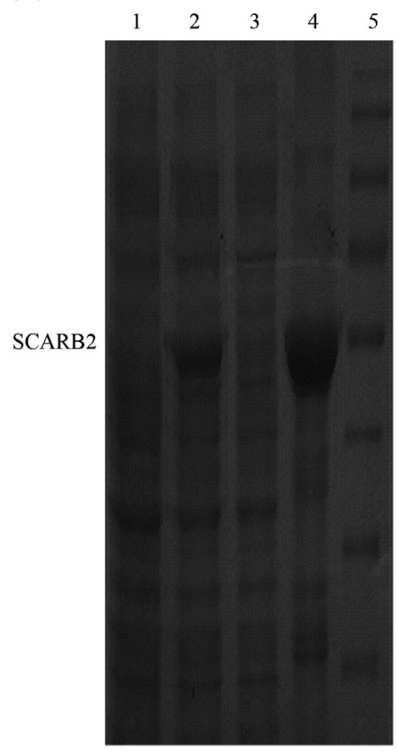

(b)

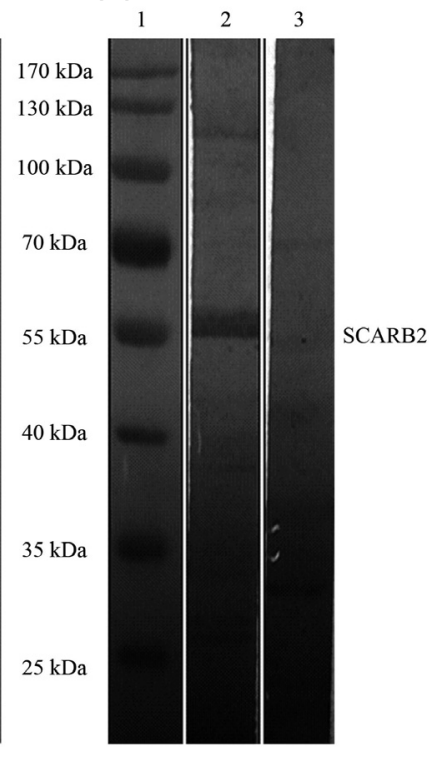

Fig. 3

SDS-PAGE and western blot analysis of recombinant SCARB2 protein (a) SDS-PAGE analysis of recombinant SCARB2 protein. Bacterial lysate transformed with pET28-SCARB2 plasmid: lane 1, without induction; lane 2 , after induction; lane 3 , soluble fraction after induction; lane 4, precipitated fraction after induction; lane 5, protein marker. (b) Western blot analysis of recombinant SCARB2 protein using His antibody. Lane 1, protein marker; total proteins of bacterial lysate with pET28a-SCARB2 plasmid: lane 2, after induction; lane3, before induction.

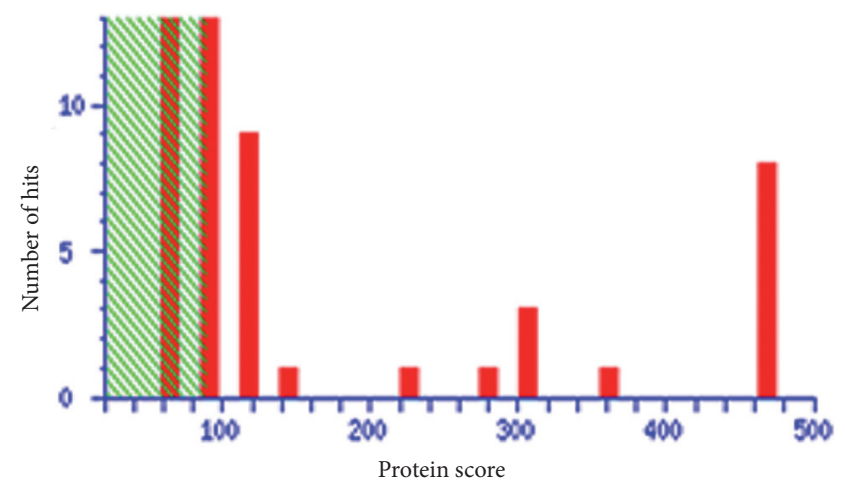

$-10^{*} \log (\mathrm{P})$, where $\mathrm{P}$-value was the probability that the observed match was a random event. Protein scores $>88$ were significant $(P<0.05)$ and false discovery rate was $0.00 \%$, showing that the protein was SCARB2 (Fig. 4).

Recombinant SCARB2 protein and EV71 virus interaction proved by ELISA

To determine the interaction between recombinant SCARB2 and EV71 or EV71-VP1 protein, the ELISA assay was used. SCARB2 reacted with EV71 and VP1 protein (Table 1). Our findings were consistent with Yamayoshi et al. (2012) who showed that SCARB2 was an EV71 receptor, and further confirmed that SCARB2 could bind with EV71 virus VP1 protein. This result also confirmed that the recombinant SCARB2 protein has good biological activity.

Table 1. Indirect ELISA of recombinant SCARB2 reaction with EV71and VP1

\begin{tabular}{lccccc}
\hline & $\begin{array}{c}\text { VP1 monoclonal } \\
\text { antibody } \\
(\mathbf{1 : 1 0 0 )}\end{array}$ & \multicolumn{2}{c}{$\begin{array}{c}\text { Negative mouse } \\
\text { serum } \\
(\mathbf{1 : 1 0 0 )}\end{array}$} & Control \\
\hline SCARB2 & EV71 & VP1 & EV71 & VP1 & \\
$(1: 1000)$ & $(1: 10)$ & $(1: 100)$ & $(1: 10)$ & $(1: 100)$ & \\
OD $_{450}$ & 1.423 & 1.274 & 0.09 & 0.08 & 0.06 \\
\hline
\end{tabular}

$B A L B / c$ mice immunization with recombinant protein $S C A R B 2$

To verify the immunoreactivity of the recombinant protein SCARB2, we have immunized BALB/c mice with the recombinant protein, and successfully obtained the mice sera containing SCARB2 polyclonal antibody. As detected by ELISA, the titer of the SCARB2 polyclonal antibody was $1: 16,000$. The immunoreactivity of the recombinant protein SCARB2 was confirmed by western blot. The protein at about $55 \mathrm{kDa}$ specifically reacted with the mice sera while no reaction was observed with the negative mice sera (Fig. 5a). These

\begin{tabular}{|c|c|c|c|c|c|c|c|c|}
\hline gijos\&161 & Mass:54825 & \multicolumn{2}{|c|}{ Sooce:469 } & \multicolumn{2}{|c|}{ Expocts.10-40 } & \multicolumn{2}{|c|}{ Matches: 7} & \\
\hline \multicolumn{9}{|c|}{ Hoeno sapiens scawenger receptor elass B, meriber 2 ( synthetic cosstruct) } \\
\hline Obscrved & $\operatorname{Mr}(\exp )$ & $\operatorname{Mr}($ cale) & Ppm & Start & End & Miss & lons & Peptede \\
\hline 1180.7133 & 1179.7060 & 1129.674 & 25.1 & 382 & -390 & 1 & - & K.RFQINTYVK.K \\
\hline 1212.5952 & 1211.5890 & 12115822 & 4.72 & 83 & -92 & 0 & 11 & R.VEEVGPYTYREE \\
\hline 1407.7194 & 1406.3122 & 1406.7024 & 5.68 & 391 & -402 & 1 & - & K.KUDDFVETGDIRT \\
\hline 16108066 & 1609.2993 & 1609.7024 & -6.66 & 83 & 95 & 1 & - & RVEEWGPYTYRELRN \\
\hline 1646.7971 & 1645.7398 & 1645.747 & 27.5 & 263 & - 275 & 0 & 89 & K.DEVLYVFPSDFCR.S \\
\hline 2129.1282 & 2178.1209 & 2173.0663 & 26.4 & 276 & -294 & 0 & 164 & RSVYTIFSDYESVQGLPAFR.Y \\
\hline $2 \$ 57.3108$ & 25663035 & 2566.2560 & 185 & 403 & -424 & 1 & 142 & RTMVFPMYLNESVHIDKETASRI \\
\hline
\end{tabular}

Fig. 4

Protein mass spectrometry analysis Mascot Score Histogram: Protein score is $-10^{\star} \log (\mathrm{P})$, where $\mathrm{P}$ was the probability that the observed match is a random event. Protein scores greater than 88 were significant $(P<0.05)$. Protein scores were derived from ions scores as a non-probabilistic basis for ranking protein hits. 
(a)

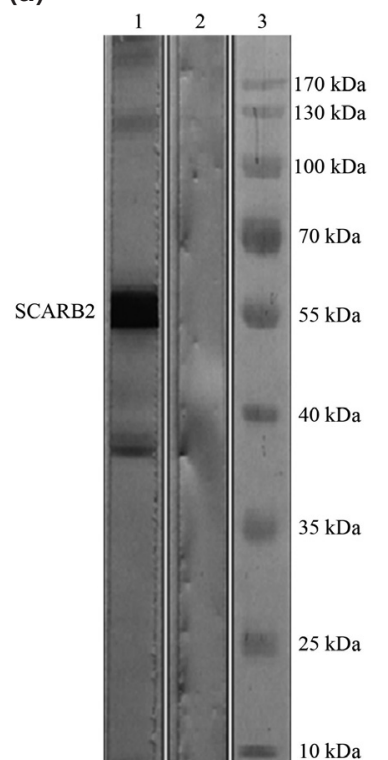

(b)

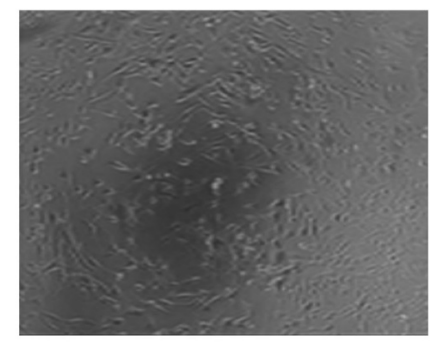

(c)

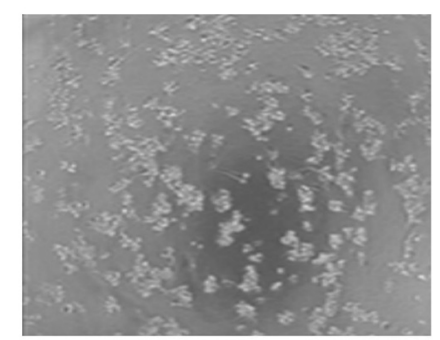

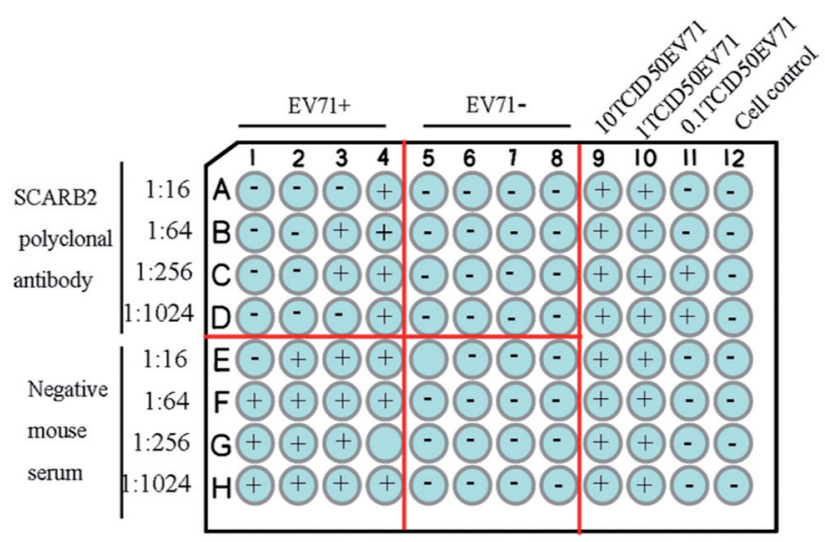

Fig. 6

Virus neutralization experiment in vitro

Immune and negative mouse sera at dilutions of 1:16, 1:64, 1:256, 1:1,024, were incubated with $100 \mathrm{TCID}_{50}$ EV71. Virus control: $10 \mathrm{TCID}_{50} \mathrm{EV}_{11}, 1$ TCID $_{50}$ EV71, 0.1 TCID $_{50}$ EV71. Cell control: non-infected RD cells. "+" indicates positive $\mathrm{CPE}$; "-" indicates negative $\mathrm{CPE}$.

Fig. 5

Immunoreactivity and activity of recombinant SCARB2 protein (a) Immunoreactivity of recombinant SCARB2 protein. Recombinant protein SCARB2 detected with: lane 1, polyclonal antibodies; lane 2, negative control sera; lane3, protein marker. (b) Non-infected RD cells. (c) Cytopathic effect of RD cells after EV71 infection.

results suggest that polyclonal antibody against recombinant SCARB2 protein generated in mice could react with purified recombinant SCARB2 protein specifically.

\section{SCARB2 polyclonal antibody neutralization test in vitro}

EV71 virus TCID $_{50}$ estimation was implemented in a 96well plate, by the cumulative cytopathic effect (Table 2). TCID $_{50}$ value of EV71 virus used in this study was $10^{-7} / \mathrm{ml}$,

meaning that $100 \mu \mathrm{l}$ of this EV71 virus diluted $10^{7}$ times could infect $50 \%$ of RD cells in one well. In order to verify the neutralizing activity of the SCARB2 polyclonal antibody (SCARB2 pAb) in mice sera, we identified a series of concentrations of SCARB2 $\mathrm{pAb}$ that may prevent RD cells from EV71 infection. In vitro neutralizing antibody titer against EV71 in the mice sera exceeded 1:256 (Fig. 6). According to these results, the immune mice serum is a good candidate for viral diagnostics.

\section{Discussion}

The pivotal event in the EV71 infection proceeding is the interaction of virus and specific receptor on the host cells

Table 2. TCID $_{50}$ calculation (inoculation dose $50 \mu \mathrm{l}$ )

\begin{tabular}{|c|c|c|c|c|c|c|c|}
\hline & \multirow{2}{*}{ Inoculation } & \multirow{2}{*}{ CPE } & \multirow{2}{*}{ No CPE } & \multicolumn{2}{|c|}{ Total } & \multirow{2}{*}{ CPE rate } & \multirow{2}{*}{ Percentage } \\
\hline & & & & CPE & No CPE & & \\
\hline $10^{-1}$ & 8 & 8 & 0 & 52 & 0 & $52 / 52$ & 100 \\
\hline $10^{-2}$ & 8 & 8 & 0 & 44 & 0 & $44 / 44$ & 100 \\
\hline $10^{-3}$ & 8 & 8 & 0 & 36 & 0 & $36 / 36$ & 100 \\
\hline $10^{-4}$ & 8 & 8 & 0 & 28 & 0 & $28 / 28$ & 100 \\
\hline $10^{-5}$ & 8 & 8 & 0 & 20 & 0 & $20 / 20$ & 100 \\
\hline $10^{-6}$ & 8 & 8 & 0 & 12 & 0 & $12 / 12$ & 100 \\
\hline $10^{-7}$ & 8 & 4 & 4 & 4 & 4 & $4 / 8$ & 50 \\
\hline $10^{-8}$ & 8 & 0 & 8 & 0 & 12 & $0 / 12$ & 0 \\
\hline $10^{-9}$ & 8 & 0 & 8 & 0 & 20 & $0 / 20$ & 0 \\
\hline $10^{-10}$ & 8 & 0 & 8 & 0 & 28 & $0 / 28$ & 0 \\
\hline
\end{tabular}


surface (Lin and Shih, 2014). The interaction between the virus and host cell receptor plays an extremely important role in early steps of viral infection. Therefore, it is very important to identify and describe receptors. Two different membrane proteins, human P-selection glycoprotein ligand-1 (Frenette et al., 2000) and human SCARB2 protein (Yamayoshi et al., 2009) have been identified as cellular receptor of EV71. SCARB2 protein is widely expressed and directly involved in systemic infection of human body. The replacement of exon 4 plays an important role in the interaction with EV71 and SCARB2 protein (Yamayoshi and Koike, 2011). This shows the widespread use of SCARB2 protein as an EV71 receptor (Yamayoshi et al., 2012).

As far as we know, most of receptors are glycoproteins and lipoproteins in cell membranes; however the number of the receptor molecules is too low to be isolated and purified. In this study, we successfully amplified SCARB2 gene and constructed the pET28a-SCARB2 vector. SCARB2 protein was expressed in an E. coli system. Purified recombinant SCARB2 protein was identified by western blot using His monoclonal antibody and mass spectrometry analysis. Expressed SCARB2 protein could interact with EV71-VP1 protein. This result is consistent with Yamayoshi's conclusion that SCARB2 is receptor of EV71virus (Yamayoshi et al., 2012). But the SCARB2 protein used in Yamayoshi's experiment was expressed by eukaryotic expression system, while our results show that the recombinant protein expressed in prokaryotic system also had good biological activity. We have successfully immunized BALB/c mice with SCARB2 protein, and further confirmed that the recombinant SCARB2 protein had good immunoreactivity. In order to verify the neutralizing activity of the anti SCARB2 sera, we performed neutralization test in vitro. The results suggested that the mice sera immunized with SCARB2 can not only neutralize EV71 virus but also decrease the CPE of RD cells infected with EV71 virus. The antibody neutralizing titer was 1:256. These results provide an experimental basis of EV71 infection and pathogenesis and help to understand the precise interaction between EV71 and SCARB2 receptor. Also the study provides options for the development of EV71 vaccine and antiviral drugs research. Furthermore, further study of the SCARB2 monoclonal antibody will provide further theoretical basis for studies of antiviral drugs.

In conclusion, SCARB2 protein was successfully expressed in a prokaryotic expression system and was effectively expressed in E. coli BL21 for the first time. Purified recombinant SCARB2 protein had a strong immunoreactivity as well as good biological activity. Sera from mice immunized with the protein could neutralize EV71 and prevent EV71 infection of RD cells. This study provides a reference for interacting mechanism between EV71 and SCARB2 receptor, and for development of prophylactic treatment against EV71 infection.
Acknowledgments. This work was supported by the Guangzhou Medical Health Science and Technology Project (No. 20161A010033), the Technology Planning Projects of Guangdong Province (No. 2014A020212697), the China Postdoctoral Science Foundation (No. 2015M582366) and the Technology Planning Project of Guangzhou (No. 201607010120

\section{References}

Blanz J, Groth J, Zachos C, Wehling C, Saftig P, Schwake M (2010): Disease-causing mutations within the lysosomal integral membrane protein type 2 (LIMP-2) reveal the nature of binding to its ligand beta-glucocerebrosidase. Hum. Mol. Genet. 19, 563-572. https://doi.org/10.1093/hmg/ddp523

Chatproedprai S, Tempark T, Wanlapakorn N, Puenpa J, Wananukul S, Poovorawan Y (2015): Unusual skin manifestation of hand, foot and mouth disease associated with coxsackievirus A6: cases report. Springerplus 4, 362. https://doi. org/10.1186/s40064-015-1143-Z

Chatproedprai S, Theanboonlers A, Korkong S, Thongmee C, Wananukul S, Poovorawan Y (2010): Clinical and molecular characterization of hand-foot-and-mouth disease in Thailand, 2008-2009. Jpn. J. Infect. Dis. 63, 229-233.

Chen P, Song Z, Qi Y, Feng X, Xu N, Sun Y, Wu X, Yao X, Mao Q, Li X, Dong W, Wan X, Huang N, Shen X, Liang Z, Li W (2012): Molecular determinants of enterovirus 71 viral entry: cleft around GLN-172 on VP1 protein interacts with variable region on scavenge receptor B 2. J. Biol. Chem. 287, 6406-6420. https://doi.org/10.1074/jbc. M111.301622

Ch'ng WC, Saw WT, Yusoff K, Shafee N (2012): Immunogenicity of a truncated enterovirus $71 \mathrm{VP} 1$ protein fused to a Newcastle disease virus nucleocapsid protein fragment in mice. Acta Virol. 55, 227-233. https://doi.org/10.4149/ av $2011 \quad 03 \quad 227$

Ding Y, Chen X, Qian B, Wu G, He T, Feng J, Gao C, Wang L, Wang J, Li X, Cao M, Peng H, Zhao C, Pan W (2015): Characterization of the antibody response against EV71 capsid proteins in Chinese individuals by NEIBM-ELISA. Sci. Rep. 5, 10636. https://doi.org/10.1038/srep10636

Du N, Cong H, Tian H, Zhang H, Zhang W, Song L, Tien P (2014): Cell surface vimentin is an attachment receptor for enterovirus 71. J. Virol. 88, 5816-5833. https://doi. org/10.1128/JVI.03826-13

Frenette PS, Denis CV, Weiss L, Jurk K, Subbarao S, Kehrel B, Hartwig JH, Vestweber D, Wagner DD (2000): P-Selectin glycoprotein ligand 1 (PSGL-1) is expressed on platelets and can mediate platelet-endothelial interactions in vivo. J. Exp. Med. 191, 1413-1422. https://doi.org/10.1084/ jem.191.8.1413

Huang SC, Chang CL, Wang PS, Tsai Y, Liu HS (2009): Enterovirus 71 -induced autophagy detected in vitro and in vivo promotes viral replication. J. Med. Virol. 81, 1241-1252. https://doi.org/10.1002/jmv.21502

Kuronita T, Eskelinen EL, Fujita H, Saftig P, Himeno M, Tanaka Y (2002): A role for the lysosomal membrane protein 
LGP85 in the biogenesis and maintenance of endosomal and lysosomal morphology. J. Cell Sci. 115, 4117-4131. https://doi.org/10.1242/jcs.00075

Kaur G, Chandra M, Dwivedi PN (2016): Phylogenetic analysis of VP2 gene of canine parvovirus and comparison with Indian and world isolates. Acta Virol. 60, 106-110. https:// doi.org/10.4149/av $201601 \quad 106$

Lee HF, Chi CS (2014): Enterovirus 71 infection-associated acute flaccid paralysis: a case series of long-term neurologic follow-up. J. Child. Neurol. 10,1283-1290. https://doi. org/10.1177/0883073813516193

Li M, Kong XP, Liu H, Cheng LX, Huang JL, Quan L, Wu FY, Hao B, Liu C, Luo B (2015): Expression of EV71-VP1, PSGL-1 and SCARB2 in tissues of infants with brain stem encephalitis. Fa Yi Xue Za Zhi 31, 97-101, 104.

Li Z, Xu L, He D, Yang L, Liu C, Chen Y, Shih JW, Zhang J, Zhao Q, Cheng T, Xia N (2014): In vivo time-related evaluation of a therapeutic neutralization monoclonal antibody against lethal enterovirus 71 infection in a mouse model. PLoS One 9, e109391. https://doi.org/10.1371/journal. pone.0109391

Lin JY, Shih SR (2014): Cell and tissue tropism of enterovirus 71 and other enteroviruses infections. J. Biomed. Sci. 21, 18. https://doi.org/10.1186/1423-0127-21-18

Lin YW, Lin HY, Tsou YL, Chitra E, Hsiao KN, Shao HY, Liu CC, Sia C, Chong P, Chow YH (2012): Human SCARB2-mediated entry and endocytosis of EV71. PLoS One 7, e30507. https://doi.org/10.1371/journal.pone.0030507

Man-Li T, Szyporta M, Fang LX, Kwang J (2012): Identification and characterization of a monoclonal antibody recognizing the linear epitope RVADVI on VP1 protein of enterovirus 71. J. Med. Virol. 84, 1620-1627. https://doi.org/10.1002/ jmv.23372

Manat Y, Shustov AV, Evtehova E, Eskendirova SZ (2016): Expression, purification and immunochemical characterization of recombinant OMP28 protein of Brucella species. Open Vet. J. 6, 71-77. https://doi.org/10.4314/ovj.v6i2.1

Ortner B, Huang CW, Schmid D, Mutz I, Wewalka G, Allerberger F, Yang JY, Huemer HP (2009): Epidemiology of enterovirus types causing neurological disease in Austria 1999-2007: detection of clusters of echovirus 30 and enterovirus 71 and analysis of prevalent genotypes. J. Med. Virol. 81, 317-324. https://doi.org/10.1002/jmv.21374

Pourianfar HR, Javadi A, Grollo L (2012): A colorimetric-based accurate method for the determination of enterovirus 71 titer. Indian. J. Virol. 23, 303-310. https://doi.org/10.1007/ $\underline{\text { s13337-012-0105-0 }}$
Sarma N (2013): Hand, foot, and mouth disease: current scenario and Indian perspective. Indian J. Dermatol. Venereol. Leprol. 79,165-175. https://doi.org/10.4103/03786323.107631

Tu PV, Thao NT, Perera D, Huu TK, Tien NT, Thuong TC, How OM, Cardosa MJ, McMinn PC (2007): Epidemiologic and virologic investigation of hand, foot, and mouth disease, southern Vietnam, 2005. Emerg. Infect. Dis. 13, 1733-1741. https://doi.org/10.3201/eid1311.070632

Wang SM, Liu CC, Tseng HW, Wang JR, Huang CC, Chen YJ, Yang YJ, Lin SJ, Yeh TF (1999): Clinical spectrum of enterovirus 71 infection in children in southern Taiwan, with an emphasis on neurological complications. Clin. Infect. Dis. 29, 184-90. https://doi.org/10.1086/520149

Xing W, Liao Q, Viboud C, Zhang J, Sun J, Wu JT, Chang Z, Liu F, Fang VJ, Zheng Y, Cowling BJ, Varma JK, Farrar JJ, Leung GM, Yu H (2014): Hand, foot, and mouth disease in China, 2008-12: an epidemiological study. Lancet Infect. Dis. 14, 308-318. https://doi.org/10.1016/S14733099(13)70342-6

Yamayoshi S, Iizuka S, Yamashita T, Minagawa H, Mizuta K, Okamoto M, Nishimura H, Sanjoh K, Katsushima N, Itagaki T, Nagai Y, Fujii K, Koike S (2012): Human SCARB2dependent infection by coxsackievirus A7, A14, and A16 and enterovirus 71. J. Virol. 86, 5686-5696. https://doi. org/10.1128/JVI.00020-12

Yamayoshi S, Fujii K, Koike S (2012): Scavenger receptor b2 as a receptor for hand, foot, and mouth disease and severe neurological diseases. Front. Microbiol. 3, 32. https://doi. org $/ 10.3389 /$ fmicb.2012.00032

Yamayoshi S, Koike S (2011): Identification of a human SCARB2 region that is important for enterovirus 71 binding and infection. J. Virol. 85, 4937-4946. https://doi.org/10.1128/ JVI.02358-10

Yamayoshi S, Yamashita Y, Li J, Hanagata N, Minowa T, Takemura T, Koike S (2009): Scavenger receptor B2 is a cellular receptor for enterovirus 71. Nat. Med. 15, 798-801. https:// doi.org/10.1038/nm.1992

Yang B, Chuang H, Yang KD (2009): Sialylated glycans as receptor and inhibitor of enterovirus 71 infection to DLD-1 intestinal cells. Virol. J. 6, 141. https://doi.org/10.1186/1743-422X-6-141

Zhang YC, Jiang SW, Gu WZ, Hu AR, Lu CT, Liang XY, Hu YR, Zhu DD, Xie L (2012): Clinicopathologic features and molecular analysis of enterovirus 71 infection: report of an autopsy case from the epidemic of hand, foot and mouth disease in China. Pathol. Int. 62, 565-670. https:// doi.org/10.1111/j.1440-1827.2012.02837.x 